\title{
Tool-life prediction under multi-cycle loading during metal forming: a feasibility study
}

\author{
Yiran $\mathrm{Hu}^{1}$, Xi Yuan ${ }^{1}$, Guojia $\mathrm{Ma}^{2}$, M.A. Masen ${ }^{1}$, and Liliang Wang ${ }^{1, *}$ \\ 1 Department of Mechanical Engineering, Imperial College, SW7 2AZ London, UK \\ 2 Science and Technology on Power Beam Processes Laboratory, Beijing Aeronautical Manufacturing Technology Research Institute, \\ 100024 Beijing, P.R. China
}

Received 30 September 2015 / Accepted 4 November 2015

\begin{abstract}
In the present research, the friction and wear behaviour of a hard coating were studied by using ball-ondisc tests to simulate the wear process of the coated tools for sheet metal forming process. The evolution of the friction coefficient followed a typical dual-plateau pattern, i.e. at the initial stage of sliding, the friction coefficient was relatively low, followed by a sharp increase due to the breakdown of the coatings after a certain number of cyclic dynamic loadings. This phenomenon was caused by the interactive response between the friction and wear from a coating tribo-system, which is often neglected by metal forming researchers, and constant friction coefficient values are normally used in the finite element (FE) simulations to represent the complex tribological nature at the contact interfaces. Meanwhile, most of the current FE simulations consider single-cycle loading processes, whereas many metal-forming operations are conducted in a form of multi-cycle loading. Therefore, a novel friction/wear interactive friction model was developed to, simultaneously, characterise the evolutions of friction coefficient and the remaining thickness of the coating layer, to enable the wear life of coated tooling to be predicted. The friction model was then implemented into the FE simulation of a sheet metal forming process for feasibility study.
\end{abstract}

Key words: TiN coating, Friction model, Sliding wear, Stamping, Multi-cycle loading

\section{Introduction}

In the metal forming industry, finite element (FE) simulations are widely used for process analysis and parameter optimisations. As the current FE simulations are mostly performed in single cycles only, this differs from the cycles experienced by industrial metal forming tools, which are normally operated for a large number of cycles. After a certain number of cyclic loadings, the tools can be damaged due to wear. It is of vital importance for engineers to understand the tribological behaviour in metal forming processes to enable tooling wear life prediction after cyclic loadings. Moreover, tools are often coated with hard coatings for the purpose of reducing friction, increasing hardness and the resistance to wear and oxidation [1]. Recently, the tribological behaviour of coated surface contacts have been characterised at a range of conditions. Cao et al. investigated the friction and wear behaviour of $\mathrm{Cu} / \mathrm{Cu}-\mathrm{MoS}_{2}$ self-lubricating coating applied on high speed steel, in which they found that the coated high speed steel had improved tribological properties [2]. Kim and Kim performed ball-on-disc

*Corresponding author: liliang.wang@imperial.ac.uk tests to examine the effects of sliding velocity and temperature on friction and wear of a multi-layered DLC coating and found that the temperature rise led to a decrease in wear rates but an increase in friction coefficient, while an increased sliding velocity resulted in reduced wear rates and friction coefficients [3]. Hol et al. developed a physical based friction model which characterised the friction as a function of surface topography, contact pressure and plastic strain $[4,5]$. Wilson et al. presented a realistic friction model for sheet metal forming [6-9]. Ersoy-Nürnberg et al. simulated wear behaviour in sheet metal forming process by using an energy approach, in which Archard's wear model was modified to introduce a variable wear coefficient [10]: instead of being a constant value, the wear coefficient obtained by the energy approach was described in terms of the accumulated wear work $[11,12]$.

It is of great importance to carry out FE simulations for multi-cycle loading to predict the tool life in metal forming processes. For a well-designed coating/substrate system, the steady state friction coefficient will last a long time. However, as the coating becomes thin and wear will be severe and friction will increase galling of both tool and blank. Karupannasamy et al. used a rotational friction tester to 


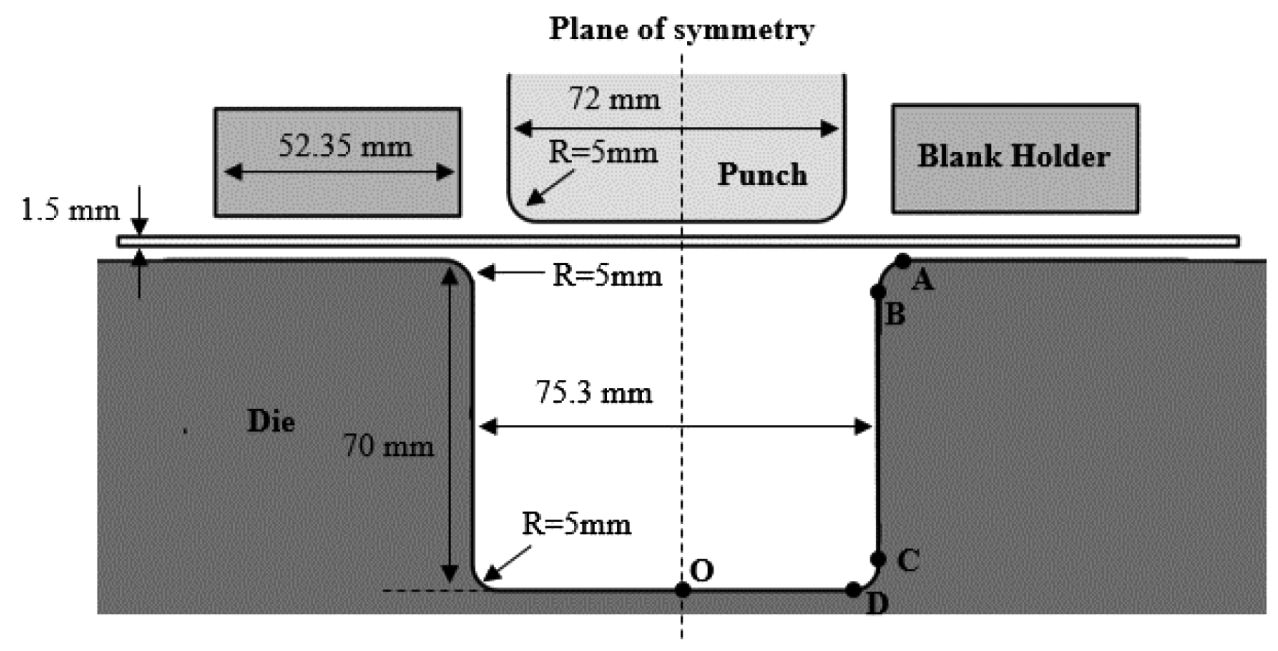

Figure 1. Geometry of the tools for the U-shape bending.

simulate the loading and reloading of the workpiece in a deep drawing process [13]. Pan and Qin investigated a multi-cycle micro-forming process in terms of temperature changes in the die after various loading cycles, in which the heat transfer between the die and workpiece was given as a function of time [14]. Moreover, Krolczyk et al. have evaluated the life of coated carbide cutting tools [15], and Fujimoto et al. tested the endurance of a DLC coated die in micro-sheet metal forming [16].

Previous tribological tests as well as models reviewed have focused on the wear and changes of the friction coefficient with both internal and external variables such as contact pressure, sliding speed etc. Most of these models can only model the constant friction coefficient at the steady-state period. However, these variables could have interactive effects on the friction coefficient and the steady-state period cannot predict the failure of a coating system. Furthermore, studies on the evolution of friction and coating thickness for coated tools under cyclic loadings are insufficient. Therefore, in this paper, the friction coefficient and wear mechanism of a hard coating are modelled by a novel friction/wear interactive model developed in [17] to characterise the evolution of the friction and predict the coated tool life.

\section{Experiment}

Bearing steel GCr15 substrates were coated with TiN by mid-frequency magnetron sputtering and cathode arc. In a ball-on-disc test, a WC-6\%Co ball with a diameter of $6 \mathrm{~mm}$ was used as a counterpart against the samples. The ball had a micro-hardness of $1780 \mathrm{HV}$, adhesion strength of $1380 \mathrm{~N} / \mathrm{cm}$ and elastic modulus of $71 \mathrm{GPa}$. A UMT-2 ball-on-disc tribometer was used. Friction coefficient, wear rate and wear volume were recorded. The sliding speed is $5 \mathrm{~mm} / \mathrm{s}$. The cross-section of the sample was examined by SEM-JEM 2010 scanning electron microscope to determine the thickness of the coating. The WS-2004 micro-scratch tester was used to examine the adherent strength. The micro-hardness and nanohardness of the samples were tested on a Wolpert Wilson Instruments Tukon 2500 hardness tester. The white-light interferometric surface profiler was used to obtain the three dimensional surface profile before and after the test. These properties of the TiN coating were used in the interactive friction model developing. More details on the experimental setup in the magnetron sputtering, ball-on-disc test and post processing can be found in reference [17].

\section{The interactive friction/wear model}

Friction and wear are two interactive responses of a coating tribo-system. A typical evolution pattern for the coefficient of friction during the lifetime of the coated system is observed in the ball-on-disc test. Initially, the coefficient of friction is rather low $\mu_{\alpha}$. With increasing time, the coating progressively wears and hard wear particles start ploughing through the coating, giving rise to an additional friction component $\mu_{p_{s}}$ (Eq. (1)) [17]. The coefficient of friction increases until it reaches a plateau $\mu_{p_{c}}$ (Eq. (2)). Because the level of friction depends on the presence of hard wear particles, in the model the ploughing friction between the ball and substrate is linked to the instantaneous coating thickness $(h)$. This ensures that once the remaining coating thickness is zero, $\mu_{p_{c}}=\mu_{p_{c}}$. The model parameters $\lambda_{1}$ and $\lambda_{2}$ provide the flexibility and, in the meanwhile, represent the physical meaning of the wear process. $\lambda_{1}$ represents the effect of the entrapped large-size wear particles. At the initial stage of wear, the wear particles are loosepowder like and do not contribute to the ploughing friction. As the wear process proceeds, the coating starts to break down and more large-size wear particles are generated and they gather into large-size wear debris. Once the size of the hard wear debris is sufficient to be entrapped between the surface asperities, the effect of the ploughing friction due to the entrapment of the wear particles is initiated. The intensity of the ploughing friction effect is characterised by the model parameter $\lambda_{2}$, which is characterised by the slope of the COF. This friction model uses time based integration algorithm to capture the evolution of the remaining coating thickness, which is updated within each calculation loop by using equation (3). The benefits become pronounced when the accumulated wear effect under varying 


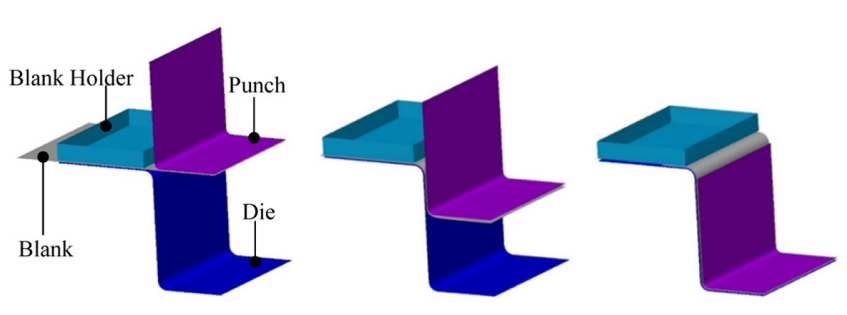

Figure 2. Schematic diagram of U-shape bending simulation.

Table 1. Material constants for the friction model.

\begin{tabular}{cccccccc}
\hline$\lambda_{2}$ & $\mu_{P_{s}}$ & $\alpha$ & $k_{\lambda 1}$ & $k_{K}$ & $\mu_{a}$ & $N_{\lambda 1}$ & $N_{k}$ \\
\hline 2 & 0.311 & 6 & $4.58 \mathrm{E} 17$ & $7.27 \mathrm{E}-23$ & 0.17 & -3.84 & 4.095 \\
\hline
\end{tabular}

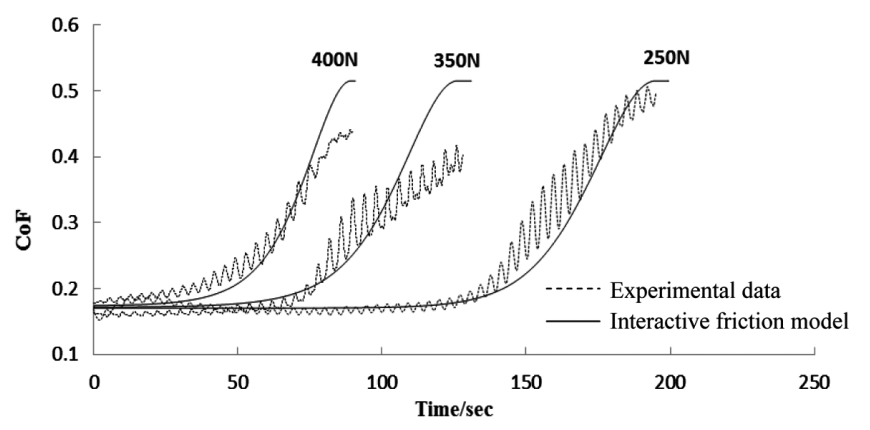

Figure 3. Evolution of friction coefficient under different loads by experimental data and friction model.

contact conditions is modelled. The classic Archard law (Eq. (4)) is modified and adopted in the present model to estimate the wear of the coating. The concept of the combined hardness (Eq. (5)) is employed to estimate the evolution of the coating hardness considering the thinning effect of the coating, in the meanwhile, the softening of the coating due to thinning is contributing to the wear rate increase (Eq. (4)). The ploughing friction, as a response to the coating thickness reduction (large wear particles entrapment), would increase correspondingly. As such, the interactive responses between friction and wear are realised in this friction model. Further details of this friction model can be found in reference [17].

$$
\mu=\mu_{\alpha}+\mu_{p_{c}}
$$

$$
\begin{gathered}
\mu_{p_{c}}=\mu_{p_{s}} \exp \left[-\left(\lambda_{1} h\right)^{\lambda_{2}}\right] \\
h=h_{0}-\dot{h} d t \\
\dot{h}=\frac{K P v}{H_{c}} \\
H_{c}=H_{s}\left(\frac{\alpha^{2}+h \beta^{2}}{\alpha+h \beta^{2}}\right) \\
\lambda_{1}=k_{\lambda_{1}} P^{N_{\lambda_{1}}} \\
K=k_{K} P^{N_{K}}
\end{gathered}
$$

The friction model parameters include load independent parameters, $\mu_{p_{s}}$, and $\lambda_{2}$, hardness ratio between coating and substrate, $\alpha$, and the coefficient of thickness, $\beta$. The model constants are $k_{\lambda_{1}}, k_{K}, N_{\lambda_{1}}$ and $N_{K}$, which relate to the evolution of friction and are determined empirically [17-21].

\section{FE simulation with the new friction model}

The friction model is implemented into FE software, PAMSTAMP, for the simulation of an U-shape bending (Figure 1). The change of pressure and friction distribution and coating thickness after different numbers of cycles are estimated by following these steps: (1) FE simulation with PAM-STAMP is run as a single cycle process (mesh size of the blank: $1.6 \mathrm{~mm}^{2}$ ), the results interested (e.g. pressure and sliding speed) of each element is exported; (2) the data obtained from PAM_STAMP is imported into a MATLAB programme created. In this programme, the multi-cycled forming calculation is carried out by running the friction model cyclically; friction coefficient and coating thickness are set as outputs; and (3) After the calculation, the result from the MATLAB programme is imported back to PAM-STAMP and thus, distribution of the results relating to each parameter can be displayed.

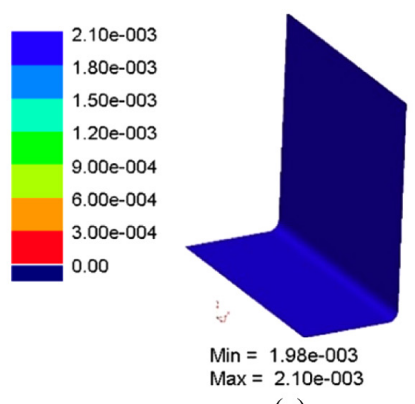

(a)

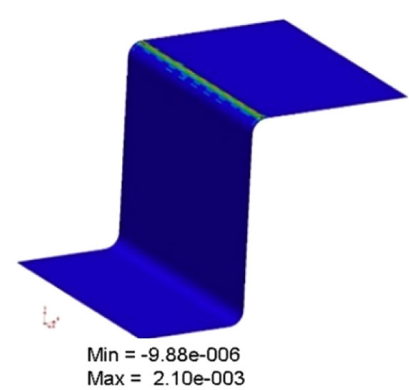

(b)

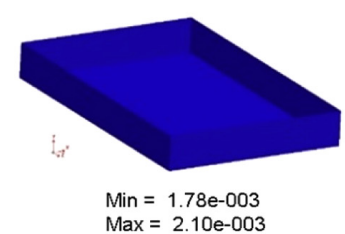

(c)

Figure 4. The remaining coating thickness distribution in the (a) punch, (b) die and (c) top blankholder, after 2000 times of forming cycles. 


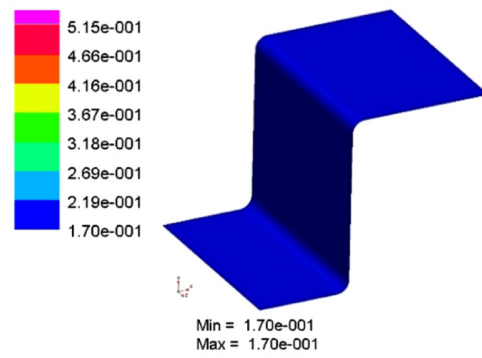

(a)

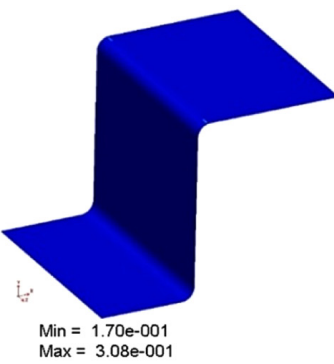

(b)

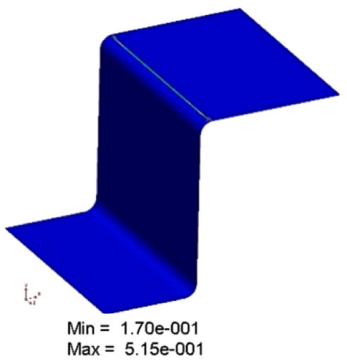

(c)

Figure 5. Local friction coefficients after (a) 500 cycles, (b) 1500 cycles, (c) 2000 cycles of forming operations.

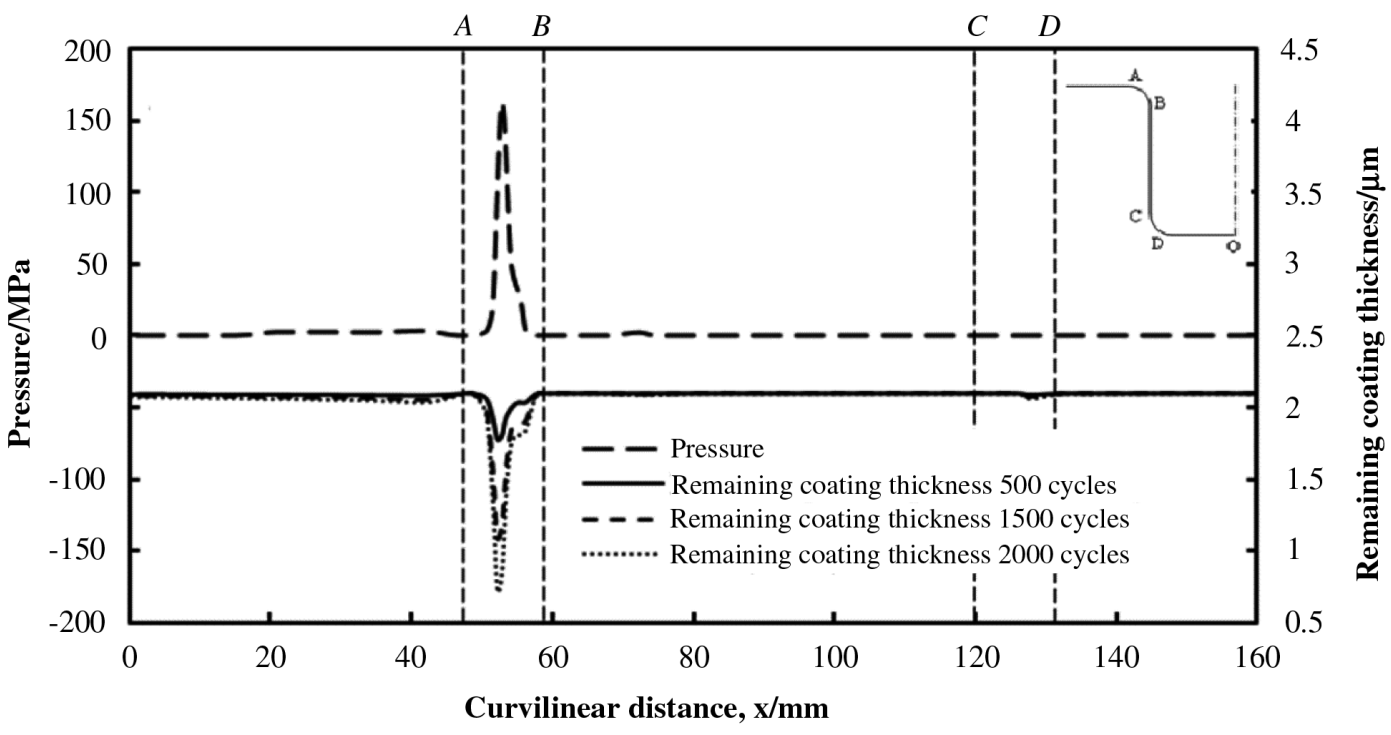

Figure 6. Prediction of contact pressure and remaining coating thickness along the curvilinear distance of the die.

This stamping process is simulated as a symmetric model in PAM-STAMP. The blank and tool geometries used in the simulation are shown in Figure 2.

\section{Results and discussion}

\subsection{Modelling of friction}

The friction model constants of the hard coating used in the interactive friction model are determined from experimental results by using a numerical integration code. The constants are listed in Table 1.

Once the model constants and parameters are determined, the evolution of friction coefficient and the breakdown time (sliding distance) of this hard coating can be predicted. Figure 3 shows the experimental results under three different loads compared by their friction modelling results. There are good agreement between the experiments and the simulated results. For the contact between TiN coating and the WC- $6 \%$ ball, the predicted friction coefficient curves start with a relatively low value of about 0.17 , after a gradual increase of friction due to ploughing friction induced by wear debris, the coating starts to break down and the friction coefficients reach approx. 0.51.

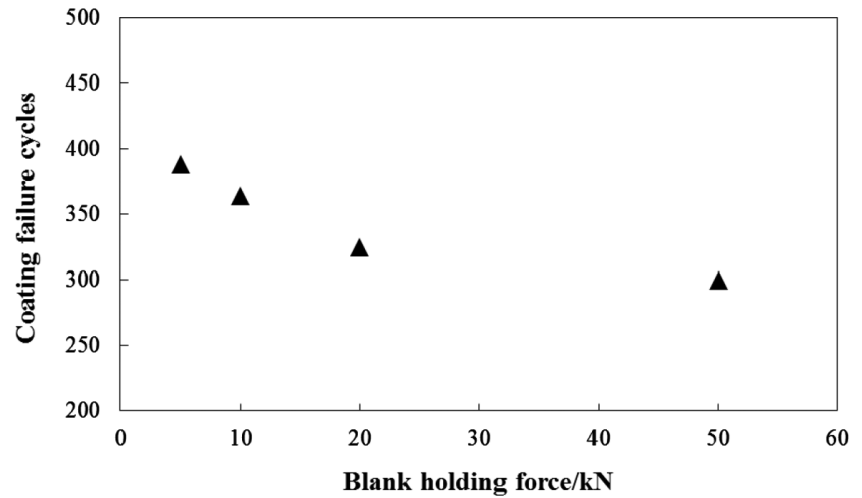

Figure 7. Predicted coating failure cycles against blank holding forces of the die.

As increased contact pressures, the coating breaks down quicker, which agrees with Archard's wear law as the coating wears faster under higher normal loads [11]. In addition, since a higher load is applied, the generation of wear debris will be faster, which consequently reduces the duration of the low friction region. 


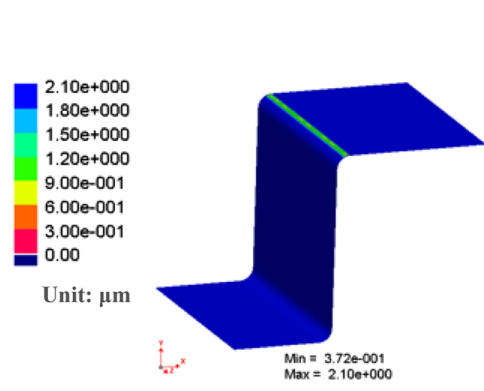

(a)

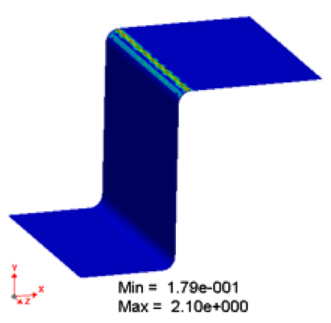

(b)

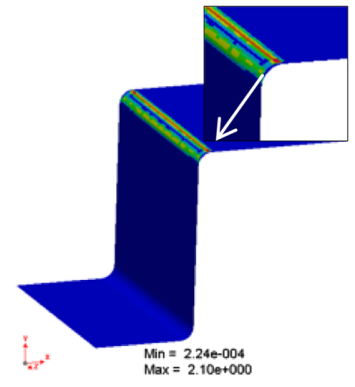

(c)

Figure 8. The remaining coating thickness distribution of the die with different blank holding forces after 300 cycles of operation. (a) $5 \mathrm{kN}$, (b) $20 \mathrm{kN}$, (c) $50 \mathrm{kN}$.

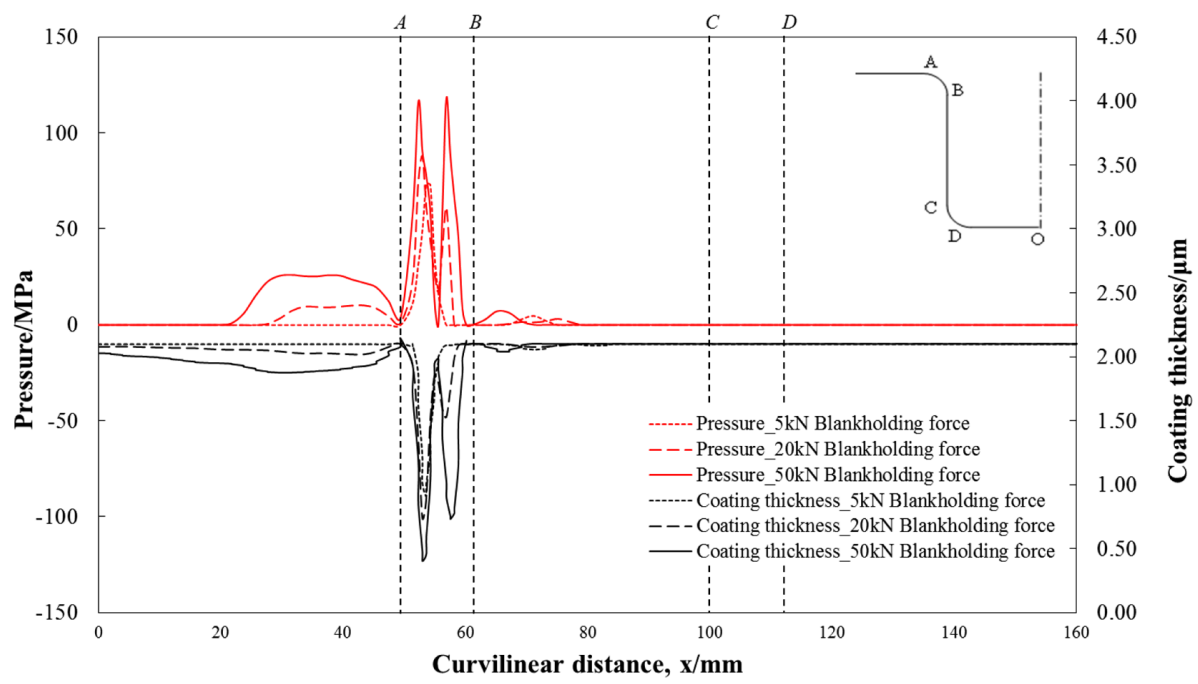

Figure 9. Simulative contact pressure and coating thickness with different blank holding along the curvilinear distance of the die, after 300 cycles of operation.

\subsection{Tool-life prediction - a feasibility study}

Most FE simulations conducted for the sheet metal forming operations as described in literature are single cycled with a constant friction coefficient/factor assigned as the boundary condition. This ignores any evolutions of the interface conditions due to the multi-cycle loadings and probably is an over-simplification of the complex tribological nature at the workpiece/tooling interface. The results shown in Figure 3 indicate that the friction coefficient evolves and the system has an interactive response to wear. Therefore, the use of a constant friction coefficient in the FE simulation, e.g. by taking the average value over the entire life time of the coating, will lead to a considerable deviation from the actual contact conditions at the tooling/workpiece interface. The implementation of the interactive friction model as described above, will enable accounting for complex evolutions in friction coefficient and wear during the metal forming processes which enables a more sensible definition of the frictional boundary conditions. Moreover, implementation of the interactive friction model will enable the estimation of the breakdown of the hard coatings and thus the life of the coated tools. In the present work, the

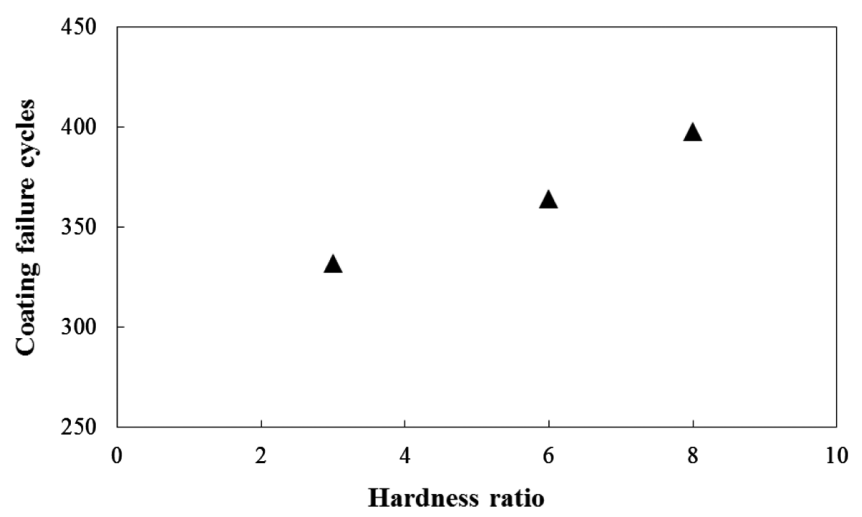

Figure 10. Predicted coating failure cycles against hardness ratio for the die.

interactive friction model is implemented into a U-shape bending simulation, as a feasibility study. The effects from process (forming cycles and blank holding force) and coating parameter (coating to substrate hardness ratio) are discussed. 


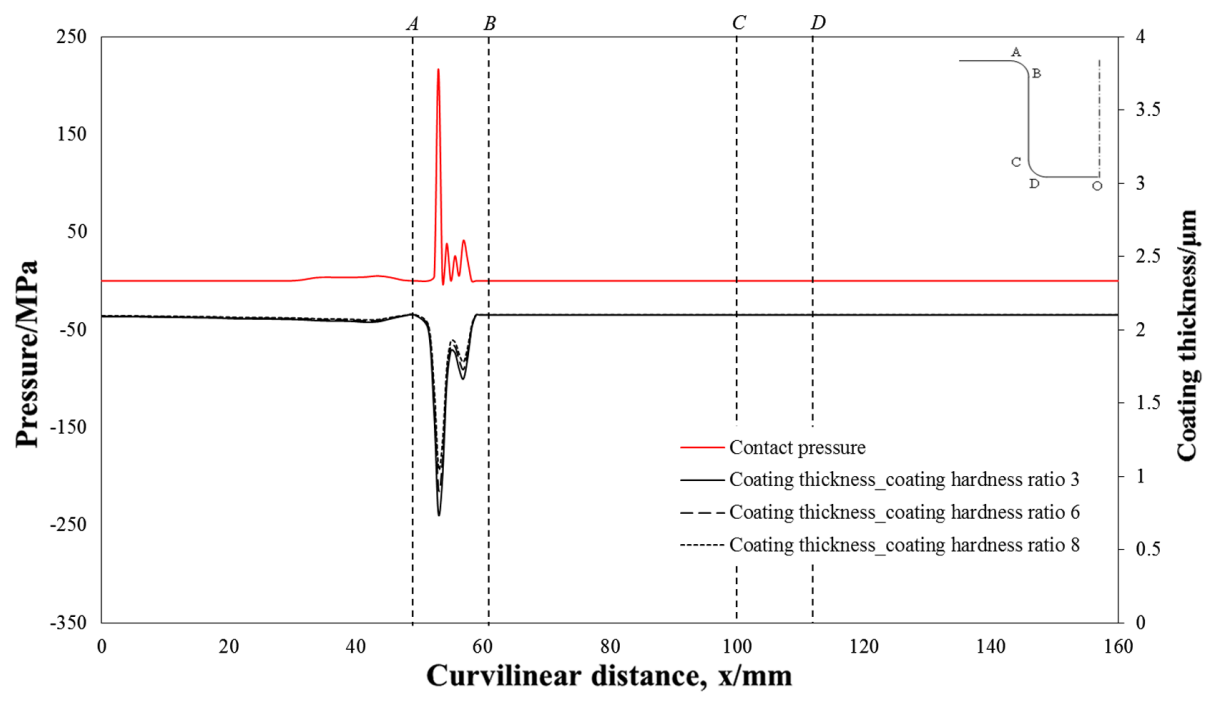

Figure 11. Simulative contact pressure and coating thickness of the die with different hardness ratio after 300 cycles of operation.

\subsubsection{Effect of the forming cycles}

The evolutions of friction distribution and coating thickness of the tools after 500, 1500 and 2000 forming cycles are obtained for a stamping speed of $75 \mathrm{~mm} / \mathrm{s}$, are obtained. Figure 4 shows the remaining coating thickness after 2000 forming cycles of the die punch and blank holder: the remaining coating thickness of the die, particularly in the entrance region, is much lower than the punch and blank holder. This can be explained as the entrance region of the die undergoes severe sliding wear caused by long accumulate sliding distance whilst locally there is a high contact pressure. Meanwhile, the friction coefficient increases due to the gradual wearing down of the coating, as shown in Figure 5: the friction coefficient in the main contact region increases to 0.308 and 0.515 after 1500 and 2000 forming cycles, respectively; while the friction coefficient of the die remained at 0.17 after 500 cycles. This result suggests that the effects of coating breakdown in the entrance region are noticeable after approx. 1500 cycles, whilst wear and the coefficient of friction observed on both the punch and the blank holders are largely changed.

This is shown more clearly in Figure 6, which shows the pressure and the remaining coating thickness distribution along the curvilinear distance of the die after 500, 1500 and 2000 forming cycles. The region indicated with " $\mathrm{AB}$ " is the die entrance region. The pressure in this region is much higher than other regions of the die. Consequently, the most severe wear of the coating occurs in this area. The lowest remaining coating thicknesses after 500, 1500 and 2000 cycles were $1.773 \mu \mathrm{m}, 1.087 \mu \mathrm{m}$ and $0.725 \mu \mathrm{m}$ respectively, compared to an initial coating thickness of $2.1 \mu \mathrm{m}$.

\subsubsection{Effect of the blank-holding force}

The effect of the blank holding force on the evolution was investigated using a set of simulations, at a stamping speed of $250 \mathrm{~mm} / \mathrm{s}$. As shown in Figure 7, the lifetime of the coated die generally reduced with the increase of the blank holding force. The coating failure cycles for the simulations with blank holding forces of $5 \mathrm{kN}, 10 \mathrm{kN}, 20 \mathrm{kN}$ and $50 \mathrm{kN}$ were 388 , 364,325 and 300 cycles, respectively. The durability of the coated tool improves as the blank holding force decreases. For instance, when the blank holding force reduced from $20 \mathrm{kN}$ to $10 \mathrm{kN}$, the tooling life increases $12 \%$.

Figure 8 shows the remaining coating thickness distribution on the coated die after 300 cycles. According to Figure 7, the coating on the die used in forming process with a blank holding force of $50 \mathrm{kN}$ will be completely removed after 300 cycles. This can also be observed in Figure 8c, where the remaining coating thickness at the die entrance region is only $2.24 \times 10^{-4} \mu \mathrm{m}$, meaning that the coating has eventually broken down and locally the coefficient of friction is very high.

Figure 9 shows the simulative contact pressure and coating thickness along the curvilinear distance of the die after 300 times of operations, with blank holding forces of $5 \mathrm{kN}$, $20 \mathrm{kN}$ and $50 \mathrm{kN}$, respectively. It can be observed that the contact pressure peaks at the die entrance region A-B, where the severe wear occurs. The higher blank holding force induced a higher peak of contact pressure in the die resulting in an increased reduction on the thickness of the coating. In addition, there was typical two-peak transient contact pressure observed at the die entrance region. The initial and secondary peaks could be caused by bending and unbending of the strip [22]. In the U-shape bending process, the blank was bent over the entrance of die radius (causing the initial pressure peak region) to create an initial curvature followed by vertical drawing over the curvature with severe contact remained at the exit of die radius (the secondary peak pressure region) until the end of the process [23]. The lowest coating thicknesses obtained were $0.91 \mu \mathrm{m}, 0.57 \mu \mathrm{m}$ and $0.40 \mu \mathrm{m}$ for the simulations with blank holding forces of $5 \mathrm{kN}, 20 \mathrm{kN}$ and $50 \mathrm{kN}$ respectively.

\subsubsection{Effect of the coating-to-substrate hardness ratio}

The effects of coating to substrate hardness ratio are also studied. These series of simulation are run at a stamping speed of $250 \mathrm{~mm} / \mathrm{s}$, a blank holding force of $10 \mathrm{kN}$ and an ambient temperature of $20{ }^{\circ} \mathrm{C}$. 
Figure 10 indicates the effects of coating hardness on the tool life. Assuming a constant substrate hardness of $500 \mathrm{HV}$, the coating hardness ratio between the coating and substrate was increased from 3 to 8 . It can be seen that the tool life improves accordingly.

Many references shows that the wear resistance of TiN coating is depends on the combined coating/substrate hardness system. Higher combined hardness gives better wear resistance generally. This conclusion agrees with the simulation result [24].

Figure 11 shows the simulative contact pressure and coating thickness along the curvilinear distance of the die after 300 times of operations, with hardness ratio between coating and substrate of 3, 6 and 8 respectively. It can be observed that the contact pressure peaked at the die entrance region A-B, and correspondingly the severe wear occurred at that region. The maximum coating thickness reduction decreased slightly with the increase of hardness ratio. The lowest coating thicknesses obtained were $0.74 \mu \mathrm{m}, 0.91 \mu \mathrm{m}$ and $1.05 \mu \mathrm{m}$ for the simulations with hardness ratio of 3,6 and 8, respectively.

\section{Conclusions}

Based on previously performed sliding wear experiments using a ball-on-disc configuration, the friction of TiN coated steel was shown to depend on the remaining coating thickness. This cross-correlation between friction and wear has been empirically modelled using an interactive friction model which enables the prediction of the evolution of the coefficient of friction and the breakdown of the coating. In this paper the feasibility of using this model to predict the remaining lifetime of tools for sheet metal forming is studied. The interactive friction model is implemented into an FE simulation for U-shape bending. The simulation shows the effects of the process parameters on the tool lifetime. After an initial period of constant low friction in the tool-work piece interface, locally, the friction will show a sudden increase. This increased friction typically occurs at a location with relatively extreme conditions (long accumulative sliding distances combined with high contact pressures).

It can be concluded that the implementation into an $\mathrm{FE}$ simulation of an empirical model that describes the interactive nature between the friction and the wear in the contact and is capable of locally assessing friction and wear parameters is potentially feasible. The distribution of coating thickness and friction coefficient after different forming cycles are predicted. Additionally, the decrease of blank holding force and increase of coating to substrate hardness ratio are predicted can extend the lifetime of coating. Further research efforts to optimise the model as well as experimentally verify the prediction are needed.

\section{References}

1. S. PalDey, S. Deevi, Mater. Sci. Eng. A 342 (2003) 58-79.

2. K. Cao, S. Lei, M. Zhang, Surf. Coat. Technol. 270 (2015) 24-32.

3. D. Kim, K. Kim, Wear 315 (2014) 95-102.

4. J. Hol, V.T. Meinders, M.B. de Rooij, A.H. van den Boogaard, Tribol. Int. 81 (2015) 112-128.

5. J. Hol, V.T. Meinders, H.J.M. Geijselaers, A.H. van den Boogaard, Tribol. Int. 85 (2014) 10-25.

6. W.R.D. Wilson, T.C. Hsu, X.B. Huang, J. Manuf. Sci. Eng. 117 (1995) 202-209.

7. W.R.D. Wilson, Adv. Technol. Plast. Japanese Soc. Tech. Plast. 4 (1990) 1667-1675.

8. H. Christensen, Proc. Inst. Mech. 184 (1969) 1013-1026.

9. W.R.D. Wilson, S. Sheu, Int. J. Mech. Sci. 30 (1988) 475-489.

10. K. Ersoy-Nürnberg, G. Nürnberg, M. Golle, H. Hoffmann, Wear 265 (2008) 1801-1807.

11. J.F. Archard, J. Appl. Phys. 24 (1953) 981-988.

12. J.F. Archard, W. Hirst, Proc. R. Soc. A Math. Phys. Eng. Sci. 236 (1956) 397-410.

13. D.K. Karupannasamy, J. Hol, M.B. de Rooij, T. Meinders, D.J. Schipper, Wear 318 (2014) 27-39.

14. W. Pan, Y. Qin, J. Mater. Process. Technol. 201 (2008) 220-225.

15. G.M. Krolczyk, P. Nieslony, S. Legutko, Arch. Civ. Mech. Eng. 15 (2013) 347-354.

16. K. Fujimoto, M. Yang, M. Hotta, H. Koyama, S. Nakano, K. Morikawa, J. Cairney, J. Mater. Process. Technol. 177 (2006) 639-643.

17. G. Ma, L. Wang, H. Gao, J. Zhang, T. Reddyhoff, Appl. Surf. Sci. 345 (2015) 109-115.

18. P. Põdra, S. Andersson, Tribol. Int. 32 (1999) 71-81.

19. A.M. Korsunsky, M.R. McGurk, S.J. Bull, T.F. Page, Surf. Coat. Technol. 99 (1998) 171-183.

20. K. Komvopoulos, Tribol. Trans. 34 (1991) 281-291.

21. A. Laukkanen, K. Holmberg, J. Koskinen, H. Ronkainen, K. Wallin, S. Varjus, Surf. Coat. Technol. 200 (2006) 3824-3844.

22. K. Hanaki, K. Kato, Adv. Technol. Plast. 1 (1984) 581-586.

23. M.P. Pereira, W. Yan, B.F. Rolfe, Wear 265 (2008) 11-12.

24. K. Holmberg, A. Matthews, in: Tribology and Interface Engineering series, B. Briscoe (Ed.), 2nd edn., Elsevier Science, 2009, pp. 232-235. 